NBER WORKING PAPER SERIES

\title{
THE INFLUENCE OF GEOGRAPHY AND MEASUREMENT IN ESTIMATING CIGARETTE PRICE RESPONSIVENESS
}

\author{
Michael F. Pesko \\ John A. Tauras \\ Jidong Huang \\ Frank J. Chaloupka, IV \\ Working Paper 22296 \\ http://www.nber.org/papers/w22296 \\ NATIONAL BUREAU OF ECONOMIC RESEARCH \\ 1050 Massachusetts Avenue \\ Cambridge, MA 02138 \\ June 2016, Revised July 2017
}

This project was funded by U01CA154248 from the National Cancer Institute (PI Frank Chaloupka). We thank the Kilts-Nielsen Data Center at The University of Chicago Booth School of Business for providing data for this manuscript (http://research.chicagobooth.edu/nielsen/). We also thank Haytham Abu Zayd for research assistance. The views expressed herein are those of the authors and do not necessarily reflect the views of the National Bureau of Economic Research.

NBER working papers are circulated for discussion and comment purposes. They have not been peer-reviewed or been subject to the review by the NBER Board of Directors that accompanies official NBER publications.

(C) 2016 by Michael F. Pesko, John A. Tauras, Jidong Huang, and Frank J. Chaloupka, IV. All rights reserved. Short sections of text, not to exceed two paragraphs, may be quoted without explicit permission provided that full credit, including $\odot$ notice, is given to the source. 
The Influence of Geography and Measurement in Estimating Cigarette Price Responsiveness Michael F. Pesko, John A. Tauras, Jidong Huang, and Frank J. Chaloupka, IV

NBER Working Paper No. 22296

June 2016, Revised July 2017

JEL No. I12,I18

\begin{tabular}{|c|c|}
\hline \multicolumn{2}{|c|}{$\underline{\text { ABSTRACT }}$} \\
\hline \multicolumn{2}{|c|}{$\begin{array}{l}\text { We use data from the Tobacco Use Supplements to the Current Population Surv } \\
2006-2015 \text { to calculate cigarette price elasticities of demand using four alternative ciga } \\
\text { price measures that compensate for the local tax environment to various extents. We } \\
\text { state-level prices and local-level prices from } 386 \text { sub-state areas of the United States. We } \\
\text { a price elasticity of total demand of }-0.38 \text { using the price measure most strongly compens } \\
\text { the local tax environment, and significantly lower elasticities for other popular cigare } \\
\text { measures. We also find greater price responsiveness for adults that are younger, higher } \\
\text { and higher educated. }\end{array}$} \\
\hline Michael F. Pesko & Jidong Huang \\
\hline Weill Cornell Medical College & Health Policy Center \\
\hline Cornell University & Institute for Health Research and Policy \\
\hline 402 East 67 th Street & University of Illinois at Chicago \\
\hline LA-216 & 1747 West Roosevelt Rd. \\
\hline New York, NY 10065 & Chicago, IL 60608 \\
\hline mip2037@med.cornell.edu & jhuang12@uic.edu \\
\hline John A. Tauras & Frank J. Chaloupka, IV \\
\hline University of Illinois at Chicago & University of Illinois at Chicago \\
\hline Department of Economics (m/c 144) & Department of Economics (m/c 144) \\
\hline College of Liberal Arts and Sciences & College of Liberal Arts and Sciences \\
\hline 601 S. Morgan Street, Room 707 & 601 S. Morgan Street, Room 713 \\
\hline Chicago, IL 60607 & Chicago, IL 60607-7121 \\
\hline and NBER & and NBER \\
\hline tauras@uic.edu & fjc@uic.edu \\
\hline
\end{tabular}




\section{Introduction}

Smoking is the largest cause of preventable disease and death in the United States, leading to more than 480,000 deaths each year (USDHHS 2014). Raising the price of cigarettes is argued to be the most effective way to reduce tobacco use (World Health Organization 2008). Several meta-analyses have found an adult cigarette price elasticity of demand estimate of -0.4 (IARC 2011; Gallet and List 2003; Chaloupka and Warner 2000), with a range of -0.2 to -0.6 (IARC 2011). Several recent price elasticity estimates provide support to the consensus estimate after correcting for cross-state border purchasing (Harding, Leibtag, and Lovenheim 2012; Lovenheim 2008; Colman and Remler 2008). However, recent cigarette tax elasticity of demand studies have found that cigarette tax responsiveness for adults ranges from -0.03 to -0.09 (Callison and Kaestner 2014; Maclean, Webber, and Marti 2014; Maclean, Kessler, and Kenkel 2015). These tax elasticity estimates are lower than price elasticity estimates in part because state and federal taxes are only $1 / 3$ of the retail price of cigarettes (Orzechowski and Walker 2015); nevertheless, even multiplying these tax elasticities by a factor of 3 to better approximate price elasticities still places these estimates on the lower end of the consensus price elasticity estimate range. Taken together, this may suggest an important role of tax avoidance in reducing cigarette price responsiveness.

The United States has a patchwork cigarette taxation system that contributes to substantial variation in cigarette prices, even within states. As of September, 2015, there were more than 600 local jurisdictions nationwide with their own cigarette tax rates or fees, with most of these taxes being in three states with low state cigarette excise taxes such as Missouri (lowest state cigarette excise tax, 109 local taxes), Virginia ( $2^{\text {nd }}$ lowest state cigarette excise tax, 93 local taxes), and Alabama (13 ${ }^{\text {th }}$ lowest state cigarette excise tax, 377 local taxes) (Campaign for Tobacco-Free Kids 2015a,b). Additionally, given the sovereign status of Native American tribes, tobacco products sold on Native American reservations often do not pay state or local taxes, potentially creating additional opportunities for tax evasion and 
avoidance, especially as state-level cigarette taxes continue to rise (Chaloupka et al. 2015). For example, New York has the highest state tax, but one analysis suggests that $17.1 \%$ of New York residents purchased their cigarettes on reservations at last purchase and paid only $39 \%$ of the off-reservation price (Chaloupka et al. 2015). Meanwhile, the lowest state-level cigarette excise tax state, Missouri, is among the 17 states without a Native American reservation. These descriptive statistics motivate our paper by suggesting that local taxes and reservations may be important sources of tax variation to use in studies of cigarette price responsiveness. To the extent that local taxes are disproportionately clustered in states with low state excise taxes, and reservations are disproportionately clustered in states with high state excise taxes, this will bias estimates of cigarette tax responsiveness using state-level data towards the null of no effect.

The main contribution of our study is to explore how price responsiveness varies depending on the price measure's ability to capture the local tax environment. The price measures that we evaluate are state-level cigarette excise taxes, state-level Tax Burden on Tobacco (TBOT) cigarette prices, aggregated prices from the Tobacco Use Supplement of the Current Population Survey (TUS-CPS), and aggregated prices from the Nielsen retail data. For the TUS-CPS prices and Nielsen prices, we explore the effect of using both state-level aggregated prices and sub-state-level aggregated prices from 386 substate areas of the United States. We argue that the TUS-CPS price best captures the local tax environment since it captures tax avoidance from Native American reservation purchasing, which is not included in any of the other three price measures. Using sub-state prices rather than state-level prices may provide greater precision in measuring who has access to the reduced tax opportunities.

Secondary contributions of our study are to explore how price elasticity estimates differ among adults of different incomes, ages, and education levels. We also consider how price elasticities vary across low and high price levels. 
Using data on smoking provided by the TUS-CPS for years 2006-2015, we find that higher statelevel cigarette taxes have a small, statistically insignificant impact on reducing overall cigarette consumption. Of our three price measures, we observed statistically significant price responsiveness for only the TUS-CPS price that best accounts for the local tax environment. The level at which cigarette prices were aggregated, whether at the state level or in 386 sub-state areas of the United States, did not result in meaningfully different estimates of price responsiveness. Collectively, our results suggest that using price measures compensating for the local tax environment and better reflecting the prices individuals face in the marketplace results in higher estimates of price responsiveness than using other popular sources of price variation that are less adept at compensating for the local tax environment.

\section{Data}

\section{A. Tobacco Use Supplement of the Current Population Survey}

We use data from the Current Population Survey (CPS), which is collected by the Bureau of Labor Statistics through telephone and face-to-face interviews. Every month the CPS surveys a sample of approximately 60,000 households to collect a wide range of demographic, labor force, and household characteristics. Data on special topics are also gathered from these same respondents in periodic supplemental surveys, including the Tobacco Use Supplement (TUS). Eight waves of the TUS have been sponsored by the National Cancer Institute (NCl) starting in $1992 .{ }^{1}$ We use the three most recent waves 2006-07, 2010-11, and 2014-15 for this analysis given the availability of consistently collected geocode information during these waves and because of our ability to link Nielsen retail data that first became available starting in 2006.

\footnotetext{
${ }^{1}$ A wave was also collected in 2000 , but with only partial questions.
} 
We use a sample consisting of 510,899 self-responding individuals ages 18 and older that reside in the continental United States. ${ }^{2}$ Proxy respondents are allowed, but we exclude these respondents because they are not asked the full range of smoking questions. We first determine if an individual is a current smoker or not using information on if an individual has smoked 100 cigarettes in their lifetime and if an individual currently smokes every day or some days. Individuals that are current smokers are asked on how many of the past 30 days they smoked cigarettes, and on average the number of cigarettes that they smoked on these days. We use this information to calculate a strictly positive monthly cigarette consumption variable for current smokers. As indicated by Table 1 , the overall smoking rate and the number of cigarettes consumed by smokers per month has declined across the eight waves of the data. The adult smoking rate was $24.5 \%$ in $1992-93$ and smokers consumed an average of 520 cigarettes monthly. By $2010-11$, the smoking rate had fallen to $16.1 \%$ and smokers consumed an average of 382 cigarettes monthly. These declines in cigarette use are associated with increases in real cigarette excise taxes (federal and state) from \$0.79 in 1992-1993 to \$2.46 in 20102011. By $2014-15$, smoking fell to $13.7 \%$ of adults and average consumption declined to 356 cigarettes monthly, despite real cigarette excise taxes declining slightly from $\$ 2.46$ per pack to $\$ 2.40$ per pack, which was a result of cigarette taxes rising less than inflation over the same time period. ${ }^{3}$

We use the rich demographic data provided in the CPS in our analysis (gender, age, race, Hispanic ethnicity, education, real family income, employment/labor force participation, and marital status). Family income is recorded from all sources over the past 12 months. We linearly impute missing household income using socio-demographic characteristics, month fixed effects, and state-level unemployment rates. All monetary values (e.g. household income, cigarette prices) were adjusted for

\footnotetext{
${ }^{2}$ Alaska and Hawaii are excluded because Nielsen data is not collected in these states.

${ }^{3}$ We documented the same phenomenon in the national cigarette prices provided by the TBOT, which rose $5.3 \%$ over this time period compared to $9 \%$ for inflation.
} 
inflation and are presented in constant January, 2011 dollars. We use self-response weights in all analyses.

Descriptive statistics for the TUS-CPS are provided in Table 2.

\section{B. Cigarette Prices}

We construct six measures of cigarette prices. For the first price measure, we match cigarette excise taxes provided by the TBOT publication. These excise taxes include federal and state taxes. We do not have data on changes in local cigarette excise taxes over time. However, as we noted earlier, the current status of local excise taxes in 2015 suggests that low state-level cigarette excise tax states of Alabama, Virginia, and Missouri have many local taxes that our state-level tax measure does not account for. Additionally, we do not have good information on tax savings from Native American reservation purchases. For this reason, we use a variety of cigarette price measures that account for the local taxes.

For the second price measure, we use the TBOT's cigarette prices, which are also inclusive of federal, state, and local taxes (Chaloupka et al. 2013). The TBOT prices are collected through an annual mail survey of retail establishments that sell cigarettes in all 50 states and Washington, DC. In recent years, approximately 15,000 to 16,000 retailers have been surveyed, with response rates in the midteens and retailer numbers vary from a few dozen to nearly 100 in a given state. We adjusted the annual cigarette taxes for the dates in which the cigarette excise tax occurred, assuming a unitary pass-through rate from taxes to prices. We matched the cigarette prices onto the TUS-CPS data using state of residence. Limitations of the TBOT data are that 1 ) it does not account for opportunities to price minimize by purchasing cigarettes in out-of-state locations or on Native American reservations, 2) it does not capture individual's propensity to consume more heavily from reduced price sources, and 3) it does not reflect prices from temporary price reductions (e.g. coupons, buy-one-get-one free promotions) (Chaloupka et al. 2013). 
We address these limitations by using two other data sources: self-reported cigarette prices provided by the TUS-CPS and Nielsen retail prices. Select Nielsen retail data is made available to academic researchers through the Kilts Center at the University of Chicago. These data contain the sales volume and prices for each UPC code at the weekly level for approximately 35,000 participating grocery, drug, mass merchandiser, and other stores. According to Kilts Center documentation, as of year-end 2011 , the amount of commodity volume captured by each store type was $53 \%$ for food stores, $55 \%$ for drug stores, $32 \%$ for mass merchandise, $1 \%$ for liquor, and $2 \%$ for convenience store. Local and state excise taxes and retailer coupons are factored into the price, but manufacturer coupons are not. One limitation of the version of the Nielsen data distributed through the Kilts Center is that it does not include stores on Native American reservations; ${ }^{4}$ therefore, similar to the TBOT prices the cigarette prices from the Nielsen data will not include reservation purchasing as a source of tax avoidance.

Our final price measure is aggregated from the TUS-CPS. In the TUS-CPS, individuals report prices for the last pack or carton purchased (depending on their usual purchase) after using discounts or coupons. We adjust carton prices to a per pack price. We create cigarette prices for area $a$ by multiplying individual i's last price paid for a pack of cigarettes by the ratio of $i$ 's monthly cigarette consumption over the average number of cigarettes consumed in the area. ${ }^{5}$

(1) price paid $_{a}=\sum_{i=1}^{n} \frac{\text { price last paid } i^{*} \frac{\text { cigarette smoked over past month } h_{i}}{\text { mean cigarettes smoked over past month }}}{n}$

The three price measures are different in a several key ways. Only the TUS-CPS price captures reservation purchasing. The Nielsen data captures the prices of cigarettes purchased within the substate area of residence at select retail establishments, whereas the TUS-CPS data captures the prices

\footnotetext{
${ }^{4}$ Based on personal correspondence with Katie Claussen Bell, Director of the Kilts Center for Marketing at the University of Chicago.

${ }^{5}$ We did not use a small number of self-reported cigarette prices in creating an area-specific average price. We did not use prices below the federal excise tax of 0.39 in 2006-07 and \$1.01 in 2010-15, or cigarette prices greater than three standard deviations from the mean within a given state/wave.
} 
that smokers pay that reside in that sub-state area, allowing smokers the opportunity to purchase cigarettes from reduced price sources within and nearby that particular area, and at a greater variety of retail stores. ${ }^{6}$ Unlike the TBOT prices, both the TUS-CPS and Nielsen data compensate for smokers purchasing more frequently from reduced-price sources.

We aggregate both the TUS-CPS prices and the Nielsen retail data prices at both the statemonth and sub-state-month levels. Local cigarette prices are assigned for counties or core based statistical areas (CBSA) that had at least one smoker with a valid cigarette price during each of the nine months of data: May, 2006; August, 2006; January, 2007; May, 2010; August, 2010; January, 2011; July, 2014; January, 2015; May, 2015. Remaining respondents were assigned a price using remaining TUS-CPS self-reported prices in the state for the TUS-CPS local price, or the prices in remaining counties not previously assigned to individuals for the Nielsen local price. We identified 386 sub-state areas that we could consistently assign a wave-month specific local price. County and CBSA codes are less likely to be provided by the CPS for individuals living in rural areas, so rural-residing individuals are more likely to be assigned the residual price. In the descriptive statistics on Table 2, we show that $39.2 \%$ of our weighted sample were assigned to a valid county, $36.4 \%$ of our sample were assigned a valid CBSA, and the remaining $24.4 \%$ were assigned to the remaining counties in the state.

Figures 1 and 2 provide illustrations of how significantly cigarette prices have changed from May, 2006 to May, 2015, both across states and oftentimes within states. The TUS-CPS price increased by as much as $\$ 4.99$ per pack over this time period (Figure 1 ), and the Nielsen price increased by as much as $\$ 5.62$ per pack (Figure 2 ). The TUS-CPS local prices have greater heterogeneity across states and within states than the Nielsen local prices, potentially due to the TUS-CPS prices allowing purchases from a wider variety of stores, including those on Native American reservations. The TUS-CPS price

\footnotetext{
${ }^{6}$ The TUS-CPS price also captures the use of both retailer and manufacturer coupons, whereas the Nielsen data only captures the use of retailer coupons.
} 
therefore has greater adjustment for tax avoidance opportunities following state cigarette excise tax increases than the Nielsen prices.

Descriptive statistics for the various cigarette prices are provided on Table 2. State and federal cigarette excise taxes were, on average, $\$ 2.36$ per pack. The TBOT price average was $\$ 5.74$ per pack, which is higher than the TUS-CPS state price of $\$ 5.09$ and the Nielsen state price of $\$ 5.21$. The TBOT price could be higher due to not accounting for opportunities to price minimize by purchasing in states with lower cigarette excise taxes, and not capturing individual's propensity to consume more heavily from reduced price sources. Factors contributing to Nielsen's higher prices may be that Nielsen prices are from select retailers, do not include manufacturer coupons, and do not include purchases made on reservations or out-of-area.

Local prices are $\$ 0.12$ higher for TUS-CPS state prices than local prices, and \$0.05 higher for Nielsen local prices than Nielsen state prices. For the Nielsen prices, the higher local price relative to the state price is due to individuals residing in higher-price areas being more likely to be sampled within the TUS-CPS. This sampling issue does not affect the TUS-CPS prices, but state prices are lower here because areas with higher prices have lower consumption, which reduces the state price relative to the local price.

\section{Anti-Smoking Sentiment and Unemployment Rate}

Anti-smoking sentiment is an important control variable in studies examining cigarette price responsiveness due to the ability of anti-smoking sentiment to influence both the treatment (e.g. cigarette prices, by applying pressure on governments to raise taxes) and the outcome of smoking (by raising the social costs of smoking, or enacting other unobserved policies that affect smoking). Studies of adult tobacco use typically include year and state fixed effects to control anti-smoking sentiment that is not varying within states across time, but this will not control for anti-smoking sentiment that does vary 
within states across time. Others have included proxies for changing anti-smoking sentiment such as indoor use laws (Callison and Kaestner 2014) and state-specific linear time trends (Goldin and Homonoff 2013). More recently, studies have begun to use smoking attitude data available directly in the TUS-CPS to create state-specific measures of anti-smoking sentiment that vary over time (Maclean, Webber, and Marti 2014; Maclean, Kessler, and Kenkel 2015).

In our study, we use a mixed approach to control for anti-smoking sentiment. We control for perceptions using questions that ask all respondents 1) if smoking should be allowed in outdoor children's playgrounds and sports fields, 2) if smoking should be allowed in bars and cocktail lounges, 3 ) if smoking is permitted at home, 4) if smoking is permitted in public parts of workplace, and 5) if smoking is permitted in private parts of workplaces. ${ }^{7}$ In these areas, respondents report if smoking should be allowed or is allowed in all areas, some areas, or not at all. We take the mean (using values of 0,1 , and 2) for all five variables within each area and year/month for all individuals residing in the area besides the respondent, and include these means (which does not include the respondent's antismoking sentiment) as five separate variables in regression models to control for changing anti-smoking sentiment over time. These area-level anti-smoking sentiment variables are listed on Table 2.

Additionally, we control for area-level unemployment rates in the same way, which may be correlated with smoking through stress (Pesko 2014; Pesko and Baum 2016), and correlated with higher taxes by helping governments to reduce deficits during economic recessions. Finally, we control for state and wave/month fixed effects to further control for unobserved components of anti-smoking sentiment.

\section{Methods}

We model a traditional cigarette demand equation, with price included as an independent variable of primary interest. We first calculate a two-part model, separately calculating price elasticities

\footnotetext{
${ }^{7}$ These questions were consistently collected in all three waves of the data.
} 
for smoking participation (extensive margin) and the number of cigarettes consumed monthly among current smokers (intensive margin). We then estimate a combined model for all respondents, using cigarettes consumed monthly as the dependent variable and setting this equal to 0 for non-smokers. We estimate the following three models:

(2) smoke $_{i a t}=a+$ price $_{a t} \beta_{1}+X_{i a t} \beta_{2}^{\prime}+$ anti sent $_{a t} \beta_{3}^{\prime}+\mathrm{\gamma}_{a}+\mathrm{\gamma}_{t}+e_{i a t}$ where subscripts denote individual $i$ living in area $a$ at time $t$. Area $a$ is either state if the specification is using a state-level cigarette excise tax or price measure, or is one of 386 units (either a county, core based statistical area, or remaining counties within the state) present in all nine months of the data if using a sub-state-level price measure. $\mathrm{B}_{1}$ is the coefficient on the price variable (price ${ }_{a t}$ ) and is our primary coefficient of interest. We control for individual-level socio-demographic characteristics $\left(\mathrm{X}_{\text {iat }}\right),{ }^{8}$ anti-smoking sentiment measures and area-level unemployment rates (anti sent ${ }_{a t}$ ), area fixed effects $\left(\gamma_{a}\right)$, and wave-month fixed effects $\left(\gamma_{t}\right)$. The area fixed effects are either state or sub-state to match the level of the price measure.

Smoke $_{\text {iat }}$ represents one of three variables: smoking on the extensive margin, intensive margin, or both margins combined. Extensive margin smoking takes a value of 0 for individuals that have not smoked at all over the past 30 days, and 1 for individuals that have. Intensive margin smoking is represented by the number of cigarettes that they have smoked over the past month in (2). Finally, smoking at both the intensive and extensive margin is captured by (3), which is the number of cigarettes that individuals have consumed over the past month, with 0 used for non-smokers.

Price $_{a t}$ is one of either six cigarette tax/price variables: 1 ) state/federal tax level, 2) TBOT statelevel cigarette price, 3) TUS-CPS cigarette price formed from self-reported cigarette prices at the state level, 4) TUS-CPS cigarette price formed from self-reported cigarette prices at the levels of county, CBSA,

\footnotetext{
${ }^{8}$ We control for income and age both linearly and quadratically to control for the likely nonlinear effects of these variables on smoking.
} 
or rest of the state, 5) Nielsen cigarette price at the state level, 6) Nielsen cigarette price at the levels of county, CBSA, or rest of the state. For all six prices, the prices vary within the nine wave-months present in the data, either across states for the four state-level cigarette price measures or across sub-state areas for the two local cigarette price measures.

One potential source of omitted variable bias that we attempt to remove from our analysis is an individuals' willingness to absorb search costs to find cheaper cigarettes. We use market-level prices to predict individual cigarette purchasing, which reduces the opportunity for search costs to be a source of omitted variable bias since market-level prices are negligibly affected by a single individuals' search preferences. Additionally, in a sensitivity analysis we explore the effect of excluding TUS-CPS prices for cigarettes not purchased in the individuals' state of residence.

We use a logit model when the dependent variable is smoking participation. We estimate

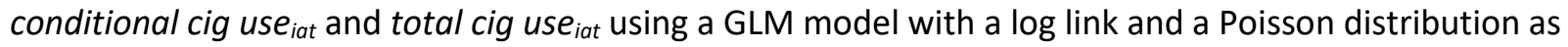
chosen by modified Park tests (Manning and Mullahy 2001). We cluster standard errors at the state level because this is the largest level at which prices may vary at, and self-response weights are used in all regression analyses to assist in making the results representative of the US population.

In our results, we present the associations between cigarette prices and cigarette use as price elasticities. In addition to showing average price elasticity estimates, we follow the best practices suggested by DeCicca and Kenkel (2015) and calculate price elasticity estimates at different price levels. We present both the average price elasticity and the price elasticity at different price levels in the same visual displays. We also present the marginal effect at different price levels in separate visual displays.

To explore heterogeneity in cigarette price responsiveness by income, age, and education, we calculate stratified models above and below the median real household income $(<\$ 40,000, \geq \$ 40,000)$, age $(<45, \geq 45)$, and education (completed high school or less, some college or more). Time preferences may be different for individuals of different income, age, and education levels, so cigarette price 
elasticity estimates may vary along these lines, too. Studies suggest that price responsiveness among adults is higher for adults that are low-income (Farrelly et al. 2001; Franks et al. 2007; Colman and Remler 2008; Goldin and Homonoff 2013), younger (Farrelly et al. 2001), and low-educated (Chaloupka 1991).

\section{Results}

In Figure 3, we calculate price elasticities at the extensive margin for our six cigarette price measures. We use the same estimation sample across all plots. We observe a statistically-insignificant extensive margin cigarette tax elasticity estimate of -0.03 for the full population. This estimate may be biased downwards if low-tax states disproportionately use local taxes, or if high-tax states disproportionately have Native American reservations that permit avoiding the state and local taxes. The extensive margin price elasticity estimates for cigarette purchases was -0.09 for the TBOT price and 0.03 for the Nielsen price. The extensive margin price elasticity estimates for the TUS-CPS price, which includes price variation from a greater variety of retail stores including on Native American reservations, was significantly higher in absolute value at -0.21 , and closely matches the consensus extensive margin price elasticity estimate of -0.20 (Chaloupka and Warner 2000). However, the price elasticity estimated using local versions of the TUS-CPS price and Nielsen price were both -0.09 .

In Figure 4, we calculate price elasticities at the intensive margin. The intensive margin cigarette tax elasticity of demand was -0.01 , and the intensive margin price elasticity estimates were -0.04 for the TВOT price, -0.12 for the Nielsen price, and -0.18 for the TUS-CPS price, which again closely matches the consensus extensive margin price elasticity estimate of -0.20 (Chaloupka and Warner 2000). When allowing for sub-state-level price variation, we observe an intensive margin price elasticity estimate of $0.16(p<0.05)$ for the TUS-CPS price and -0.02 for the Nielsen price. The TUS-CPS price, which 
compensates for reservation purchasing, again shows significantly greater price responsiveness than other price measures.

In Figure 5, we calculate price elasticities of total cigarette demand. ${ }^{9}$ The price elasticity estimate using cigarette taxes was -0.03 , which is consistent with small tax elasticity estimate found in other recent studies (DeCicca and Kenkel 2015; Callison and Kaestner 2014; Maclean, Kessler, and Kenkel 2015). Given that cigarette taxes consist of approximately $1 / 3$ of the price of cigarettes, this suggests a corresponding price elasticity estimate of roughly -0.09 , which is similar to our estimate of the total price elasticity of -0.10 for the TBOT price and -0.12 for the Nielsen price. However, we again see evidence of significantly greater price responsiveness when using the TUS-CPS price, $-0.38(p<0.05)$ when using the state measure and $-0.27(p<0.05)$ when using the sub-state measure. The TUS-CPS state price elasticity estimates ranged from a low of -0.22 at a price level of $\$ 3$ and -0.52 at a price level of $\$ 7$, but these differences were not statistically significant from the average price elasticity estimate.

In Online Figure 2, we explore the sensitivity of the greater estimate of price responsiveness when using an aggregated TUS-CPS price measure that excludes out-of-state purchases. This helps to make the TUS-CPS prices more similar to the TBOT and Nielsen prices, which do not include out-of-state prices. Using the same estimation sample that we used previously, we calculate a total margin price elasticity estimate that is similar regardless of whether we use the modified TUS-CPS price measure (price elasticity $=-0.34$ ) or original TUS-CPS price measure (price elasticity $=-0.38$ ). This provides evidence that other differences than out-of-state-purchases account for the differences in estimated price elasticities between the TUS-CPS price and the Nielsen and TBOT prices. These other differences

\footnotetext{
${ }^{9}$ In Online Table 1, we show the full regression results for models using total cigarette demand as the dependent variable. The marginal effects of prices on total cigarette demand at different price levels are shown in Online Figure 1.
} 
include the TUS-CPS price capturing sales from a wider variety of retailers, including those on reservations.

We estimate various stratified models for the effect of cigarette excise taxes and prices on total cigarette demand. Tax elasticities were similar for adults of different education and income levels, but were greater in absolute value for young adults (tax elasticity $=-0.09, p<0.05$ ). Younger adults were also more price responsive when using either the TBOT prices (Figure 7) or the Nielsen state prices (Figure 8). When using the ТВОТ prices, higher educated individuals were also more price responsive than lower educated individuals (price elasticity of -0.18 versus -0.06 ). Higher educated individuals were also more price responsive than lower educated individuals when using the Nielsen state prices $(-0.23$ versus 0.04); additionally, the price elasticity appeared greater in absolute value for higher income individuals as well $(-0.06$ versus -0.18$)$. Finally, price elasticities using the TUS-CPS state price are similar to the Nielsen price for higher income individuals $(-0.67$ versus -0.08$)$ and higher educated individuals $(-0.63$ versus -0.18 ), but were not any different for young and old adults. Collectively, our results suggest greater price responsiveness among adults that are younger, higher income, and higher educated.

\section{Discussion}

In this paper, we demonstrate significant differences in cigarette price responsiveness estimates depending on the price measure used. The TUS-CPS price best captures the local tax environment by including a wider variety of store types, including stores on reservations, and has the highest estimated price elasticity of demand. The state-level TUS-CPS price elasticity of demand estimate was -0.38 , which is consistent with the consensus price elasticity of demand estimate of -0.4. The state-level TUS-CPS price elasticity of demand estimate was little affected by removing prices from out-of-state purchases. The level of aggregation of cigarette prices, whether at the state-level or local-level, also had little 
impact on estimates of cigarette price responsiveness at the total margin (extensive + intensive), but did have discernible effects on price responsiveness at either the intensive or extensive margin.

One explanation for the low price responsiveness estimated from cigarette taxes, the TBOT price, and the Nielsen price is that these prices may not reflect the prices that consumers realistically face on the market, in part by failing to account for the local tax environment from reservation purchasing, for example. One possible interpretation of our results is that policymakers should enact policies to raise the prices that individuals actually pay for cigarettes rather than enacting new taxes that can be avoided. If policymakers can raise the prices that individuals actually pay for cigarettes, our results suggest that smoking rates can continue to be significantly reduced, even among adults. One practical recommendation is that policy efforts aimed at tax harmonization may be more effective than non-coordinated tax increases that contribute to greater local price variation. For example, expanding tax harmonization efforts with Native American reservations ${ }^{10}$ and other states and/or setting a floor price for cigarettes could help to reduce price differentials.

Our results also suggest a concerning pattern of cigarette prices, regardless of the price measure used, having little impact on cigarette consumption for low educated and low income individuals. While significant attention has been paid recently to the effect of the opioid epidemic on low socioeconomic status (SES) individuals (Case and Deaton 2015), our results suggest the need to provide more specific assistance to help low-SES individuals to quit smoking. Smoking rates are notoriously high among lowSES individuals; for example, $31.5 \%$ of people with less than a high school education smoke (Centers for Disease Control and Prevention 2017). Our results suggest the need to identify tobacco control policies of greater benefit to low-SES status individuals. One recent study found that the Medicaid expansion in

\footnotetext{
${ }^{10}$ Several state governments have tax harmonization arrangements with Native American reservations currently. Arrangements include quote or allotment systems in which the tribe receives a quantity of tax-exempt products for sale to their members, and compacts in which the tribe collects part of all of the cigarette excise tax, but the tribe then receives some or all of the revenue from it (Chaloupka et al. 2015).
} 
2014 increased utilization of smoking cessation medications by $36 \%$ in states that expanded Medicaid compared to states that did not (Maclean, Pesko and Hill 2017). Therefore, Medicaid smoking cessation programs may be an important component of a tobacco control environment of greater benefit to lowSES status individuals. Continuing to develop and evaluate tobacco control policies that benefit low-SES status individuals is an important area for future research. 


\section{References}

Callison, Kevin, and Robert Kaestner. 2014. "Do Higher Tobacco Taxes Reduce Adult Smoking? New Evidence of the Effect of Recent Cigarette Tax Increases on Adult Smoking." Economic Inquiry 52 (1): 155-72. doi:10.1111/ecin.12027.

Campaign for Tobacco-Free Kids. 2015. "Local Government Cigarette Tax Rates \& Fees." Washington, DC. https://www.tobaccofreekids.org/research/factsheets/pdf/0304.pdf.

Campaign for Tobacco-Free Kids. 2015. "Local Cigarette Excise Taxes in the United States." Washington, DC. Private data.

Case, Anne., and Angus Deaton. 2015. "Rising Morbidity and Mortality in Midlife Among White NonHispanic Americans in the $21^{\text {st }}$ century." PNAS 112 (49): 15078-15083. doi:

$10.1073 /$ pnas. 1518393112

Centers for Disease Control and Prevention. 2017. Cigarette Smoking and Tobacco Use Among People of Low Socioeconomic Status. Last updated Feb 3, 2017 [accessed Jun 26]. https://www.cdc.gov/tobacco/disparities/low-ses/index.htm.

Chaloupka, Frank J. 1991. "Rational Addictive Behavior and Cigarette Smoking." Journal of Political Economy 99 (4): 722-42. doi:10.1086/261776.

Chaloupka, Frank J., Sarah Matthes Edwards, Hana Ross, Megan Diaz, Marin Kurti, Xin Xu, Michael Pesko, David Merriman, and Hillary DeLong. 2015. Preventing and Reducing Illicit Tobacco Trade in the United States. http://www.cdc.gov/tobacco/stateandcommunity/pdfs/illicit-trade-report-121815508tagged.pdf.

Chaloupka, Frank J., John A. Tauras, Julia H. Strasser, Gordon Willis, James T. Gibson, and Anne M. Hartman. 2013. "A Comparison of Alternative Methods for Measuring Cigarette Prices." Tobacco Control, 1-6. doi:10.1136/tobaccocontrol-2013-051320.

Chaloupka, Frank J., and Kenneth E. Warner. 2000. "Chapter 29 The Economics of Smoking." In Handbook of Health Economics, edited by A. J. Culyer and J. P. Newhouse, 1:1539-1627. doi:10.1016/S1574-0064(00)80042-6.

Colman, Gregory J., and Dahlia K. Remler. 2008. "Vertical Equity Consequences of Very High Cigarette Tax Increases: If the Poor Are the Ones Smoking, How Could Cigarette Tax Increases Be Progressive?" Journal of Policy Analysis and Management 27 (2): 376-400. doi:10.1002/pam.20329.

DeCicca, Philip, and Donald Kenkel. 2015. "Synthesizing Econometric Evidence: The Case of Demand Elasticity Estimates." Risk Analysis 35 (6): 1073-85. doi:10.1111/risa.12363.

Farrelly, Matthew, Jeremy Bray, Terry Pechacek, and Trevor Woollery. 2001. "Response by Adults to Increases in Cigarette Prices by Sociodemographic Characteristics." Southern Economic Journal 68 (1): 156-65. doi:10.2307/1061518.

Franks, Peter, Anthony F. Jerant, J. Paul Leigh, Dennis Lee, Alan Chiem, Ilene Lewis, and Sandy Lee. 2007. "Cigarette Prices, Smoking, and the Poor: Implications of Recent Trends." American Journal of Public Health 97 (10): 1873-77. doi:10.2105/AJPH.2006.090134. 
Gallet, Craig A., and John A. List. 2003. "Cigarette Demand: A Meta-Analysis of Elasticities." Health Economics 12 (10): 821-35. doi:10.1002/hec.765.

Goldin, Jacob, and Tatiana Homonoff. 2013. "Smoke Gets in Your Eyes: Cigarette Tax Salience and Regressivity." American Economic Journal: Economic Policy 5 (1): 302-36. doi:10.1257/pol.5.1.302.

Harding, Matthew, Ephraim Leibtag, and Michael F. Lovenheim. 2012. "The Heterogeneous Geographic and Socioeconomic Incidence of Cigarette Taxes: Evidence from Nielsen Homescan Data." American Economic Journal: Economic Policy 4 (4): 169-98. doi:10.1257/pol.4.4.169.

IARC Handbooks of Cancer Prevention. 2011. Effectiveness of Tax and Price Policies in Tobacco Control. Vol. 14. Lyon, France. https://www.iarc.fr/en/publications/pdfsonline/prev/handbook14/handbook14.pdf.

Lovenheim, Michael F. 2008. "How Far to the Border?: The Extent and Impact of Cross-Border Casual Cigarette Smuggling." National Tax Journal 61 (1): 7-33.

Maclean, Johanna C., Asia S. Kessler, and Donald S. Kenkel. 2015. "Cigarette Taxes and Older Adult Smoking: Evidence from the Health and Retirement Study." Health Economics. doi:10.1002/hec.3161.

Maclean, Johanna C., Douglas A. Webber, and Joachim Marti. 2014. "An Application of Unconditional Quantile Regression to Cigarette Taxes." Journal of Policy Analysis and Management 33 (1): 188210. doi:10.1002/pam.21724.

Maclean, Johanna C., Michael F. Pesko, and Steven C. Hill. 2017. "The Effect of Insurance Expansions on Smoking Cessation Medicaton Use: Evidence from Recent Medicaid Expansions." NBER, Working Paper No. 23450. doi:10.3386/w23450.

Manning, Willard G., and John Mullahy. 2001. "Estimating Log Models: To Transform or Not to Transform?" Journal of Health Economics 20 (4): 461-94. doi:10.1016/S0167-6296(01)00086-8.

Orzechowski and Walker. 2015. "The tax burden on tobacco: Historical compilation 2015." Arlington, VA.

Pesko, Michael F. 2014. "Stress and Smoking: Associations with Terrorism and Causal Impact." Contemporary Economic Policy 32 (2): 351-371. doi:10.1111/coep.12021.

Pesko, Michael F., and Christopher F. Baum. 2016. "The self-medication hypothesis: Evidence from terrorism and cigarette accessibility." Economics \& Human Biology 22: 94-102. doi:10.1016/j.ehb.2016.03.007.

U.S. Department of Health and Human Services. 2014. The Health Consequecnes of Smoking--50 Years of Progress: A Report of the Surgeon General. Atlanta, Georgia. https://www.surgeongeneral.gov/library/reports/50-years-of-progress/

World Health Organization. 2008. WHO Report on the Global Tobacco Epidemic, 2008: The MPOWER package. Geneva, Switzerland. http://www.who.int/tobacco/mpower/mpower_report_full_2008.pdf 
Table 1: Smoking Among Adults

\begin{tabular}{|c|c|c|c|}
\hline Year & $\begin{array}{c}\text { Smoking } \\
\text { Rate }\end{array}$ & $\begin{array}{c}\text { Conditional 30 Day Cigarette } \\
\text { Consumption }\end{array}$ & $\begin{array}{c}\text { Mean Population-Weighted Real Fed. } \\
\text { and State Cigarette Excise Taxes }\end{array}$ \\
\hline $1992-93$ & 24.46 & 519.56 & $\$ 0.79$ \\
\hline $1995-96$ & 23.55 & 509.89 & $\$ 0.84$ \\
\hline $1998-99$ & 22.06 & 486.95 & $\$ 0.89$ \\
\hline $2001-02$ & 20.96 & 456.94 & $\$ 1.06$ \\
\hline 2003 & 18.90 & 445.49 & $\$ 1.34$ \\
\hline $2006-07$ & 18.49 & 426.13 & $\$ 1.46$ \\
\hline $2010-11$ & 16.08 & 382.17 & $\$ 2.46$ \\
\hline $2014-15$ & 13.73 & 355.98 & $\$ 2.40$ \\
\hline
\end{tabular}

Note: Smoking data are derived from the Tobacco Use Supplement of the Current Population Survey. Cigarette tax data from the Tax Burden on Tobacco (in 2011 dollars) are merged onto the same data from the Tobacco Use Supplement of the Current Population Survey to show the tax rate experienced by respondents. 
Table 2: Descriptive Statistics for Adults in the TUS-CPS, Years 2006-2015, N = 510,899

\begin{tabular}{|c|c|c|}
\hline & Mean & Standard Deviation \\
\hline \multicolumn{3}{|l|}{ TUS-CPS Data } \\
\hline \multicolumn{3}{|l|}{ Individual Level } \\
\hline Male & 0.519 & - \\
\hline Age & 46.931 & 17.661 \\
\hline White & 0.792 & - \\
\hline Black & 0.124 & - \\
\hline American Indian, Alaskan Native & 0.010 & - \\
\hline Asian, Hawaiian Pacific Islander & 0.057 & - \\
\hline Other Race & 0.016 & - \\
\hline Hispanic & 0.155 & - \\
\hline Less than High School & 0.113 & - \\
\hline High School Only & 0.279 & - \\
\hline More than High School & 0.608 & - \\
\hline Family Income (Top Coded at $\$ 75,000$ ) & $\$ 47,107.74$ & $\$ 25,437.11$ \\
\hline Family Income Top Category & 0.317 & - \\
\hline Married (No) & 0.506 & - \\
\hline Married (Yes) & 0.494 & - \\
\hline Employed and Working & 0.613 & - \\
\hline Unemployed & 0.043 & - \\
\hline Not In Labor Force & 0.344 & - \\
\hline \multicolumn{3}{|l|}{ Area Level } \\
\hline Area Type: County & 0.392 & - \\
\hline Area Type: Core Based Statistical Area & 0.364 & - \\
\hline Area Type: Residual & 0.244 & - \\
\hline Unemployment Rate & 0.059 & 0.033 \\
\hline $\begin{array}{l}\text { Smoking Not Permitted in Home (range: } 0-2,2 \text { is } \\
\text { strongest level of restriction) }\end{array}$ & 1.787 & 0.105 \\
\hline $\begin{array}{l}\text { Smoking Not Permitted in Private Parts of Workplace } \\
\text { (range: } 0-2,2 \text { is strongest level of restriction) }\end{array}$ & 1.947 & 0.051 \\
\hline $\begin{array}{l}\text { Smoking Not Permitted in Public Parts of Workplace } \\
\text { (range: } 0-2,2 \text { is strongest level of restriction) }\end{array}$ & 1.855 & 0.086 \\
\hline $\begin{array}{l}\text { Anti-Smoking Sentiment for Bars/Clubs (range: } 0-2,2 \text { is } \\
\text { strongest level of sentiment) }\end{array}$ & 1.475 & 0.165 \\
\hline $\begin{array}{l}\text { Anti-Smoking Sentiment for Children's } \\
\text { Playgrounds/Sports Fields (range: } 0-2,2 \text { is strongest level } \\
\text { of sentiment) }\end{array}$ & 1.485 & 0.148 \\
\hline \multicolumn{3}{|l|}{ Cigarette Prices (in 2011 dollars) } \\
\hline State and Federal Taxes & 2.36 & 1.01 \\
\hline Tax Burden on Tobacco Cigarette Prices & 5.74 & 1.30 \\
\hline TUS-CPS State Price & 5.09 & 1.07 \\
\hline TUS-CPS Local Price & 5.21 & 1.35 \\
\hline
\end{tabular}




\begin{tabular}{|l|l|l|}
\hline Nielsen State Price & 5.42 & 1.33 \\
\hline Nielsen Local Price & 5.47 & 1.44 \\
\hline
\end{tabular}


Figure 1: Difference in Self-Reported Cigarette Prices from the Tobacco Use Supplement of the Current Population Survey from May 2015 to May, 2006 (in

Dollars).

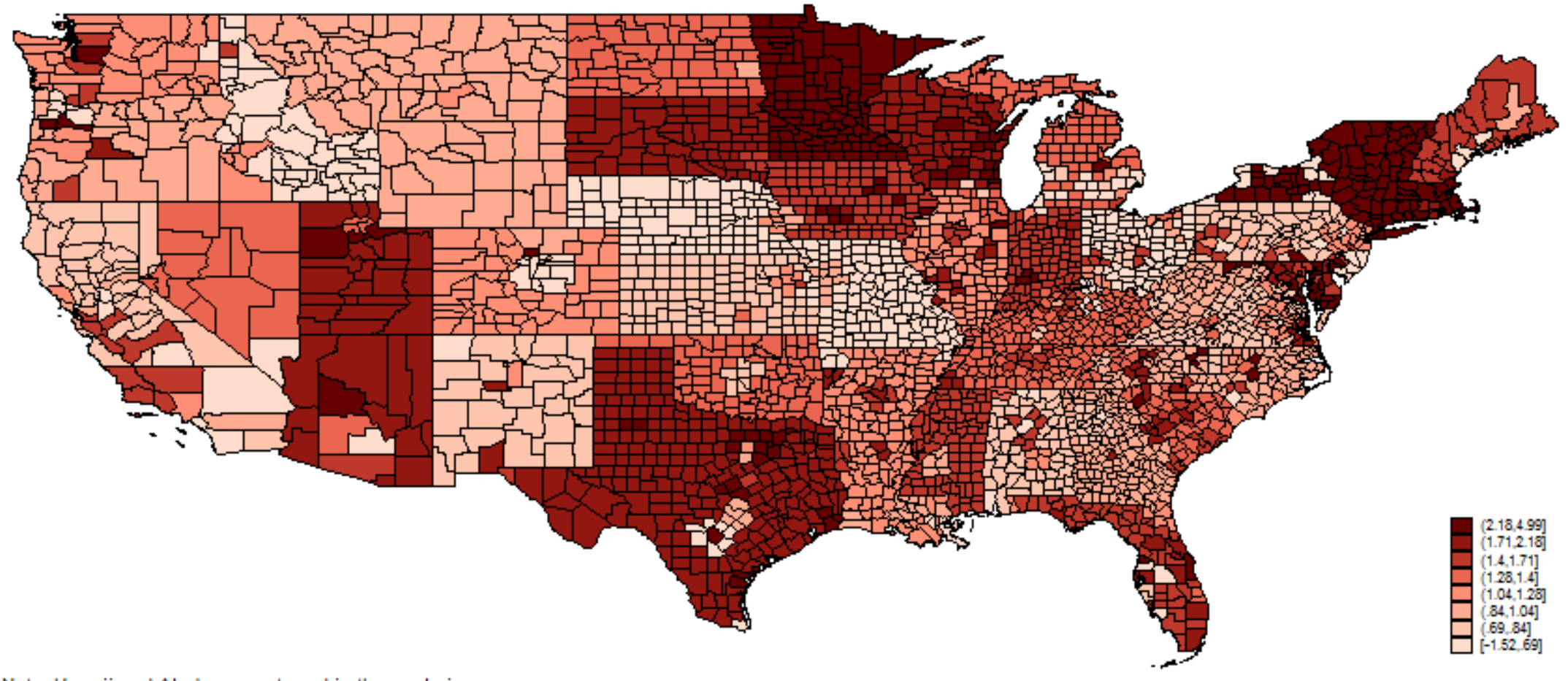

Note: Hawaii and Alaska are not used in the analysis. 
Figure 2: Difference in Self-Reported Cigarette Prices from Nielsen Retail Data from May 2015 to May, 2006 (in Dollars).

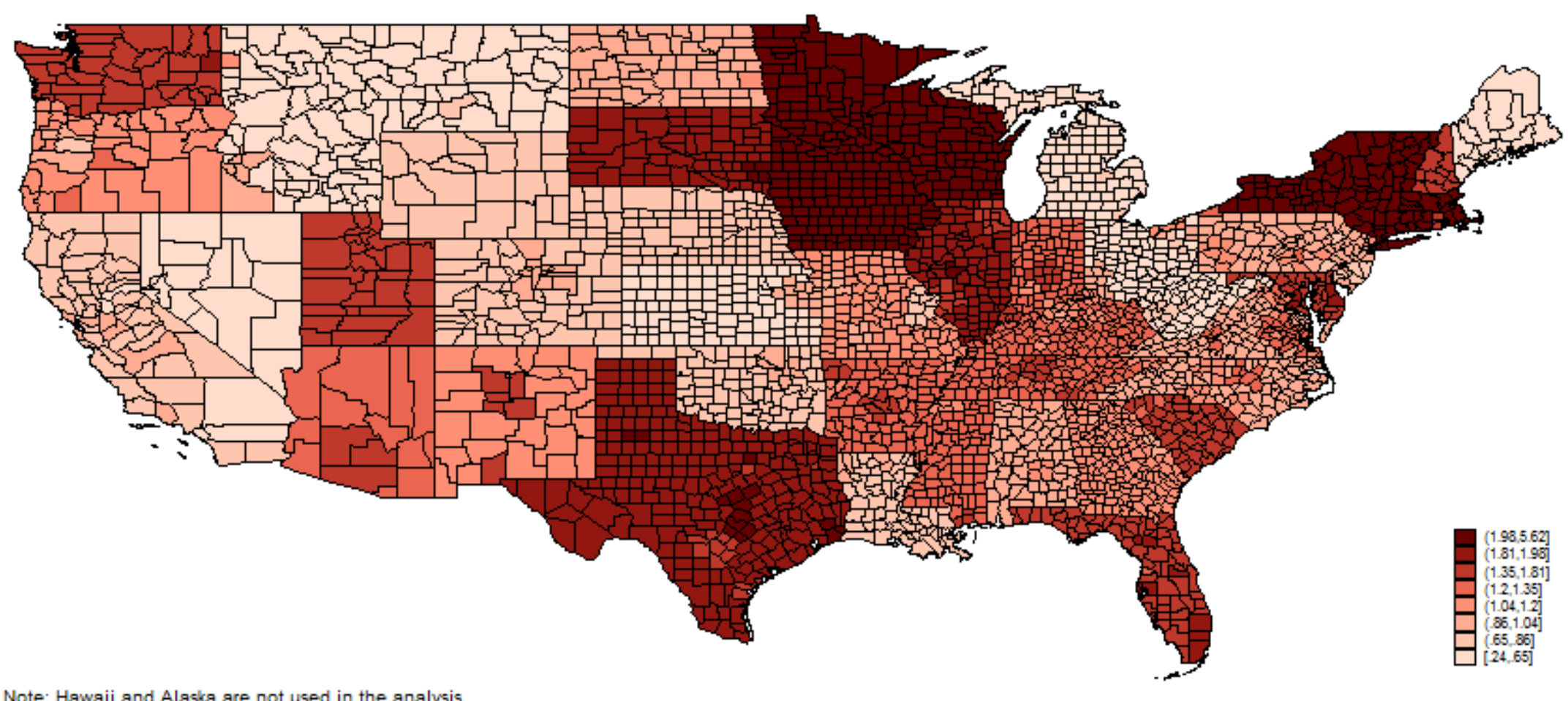

Note: Hawaii and Alaska are not used in the analysis. 
Figure 3: Smoking Participation Price Elasticities Using Six Cigarette Price Measures, 2006-2015
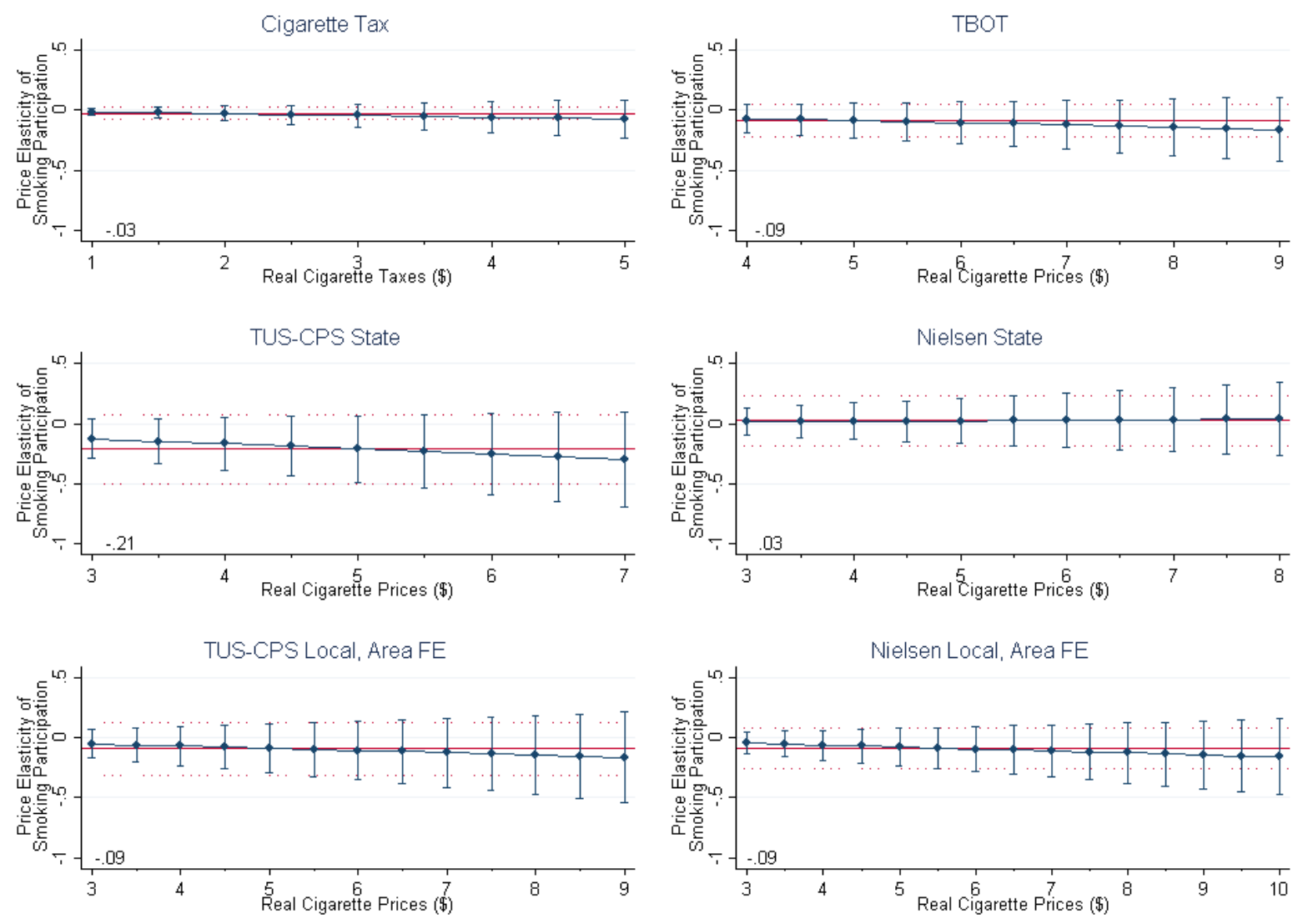

Notes: Smoking prevalence price elasticities are estimated using a logit model. Horizontal lines represent the average price elasticity and its $95 \%$ confidence interval. All regressions control for individual characteristics (gender, age, race/ethnicity, education, income, marital status, employment status), area-level characteristics (unemployment rate, indexes for smoking prohibitions in homes, public parts of workplaces, and private parts of workplaces, and anti-smoking sentiment measures for bars/clubs and playgrounds/sports fields), wave-by-month fixed effects, and either state fixed effects (first four graphs using state-level tax/price measures) or sub-state area fixed effects (last two graphs using local price measures). + Marginal effect is significant at the 5 percent level compared to the marginal effect at the lowest price level. * Average price elasticity significant at the 5 percent level. 
Figure 4: Conditional Cigarette Demand Price Elasticities Using Six Cigarette Price Measures, 2006-2015
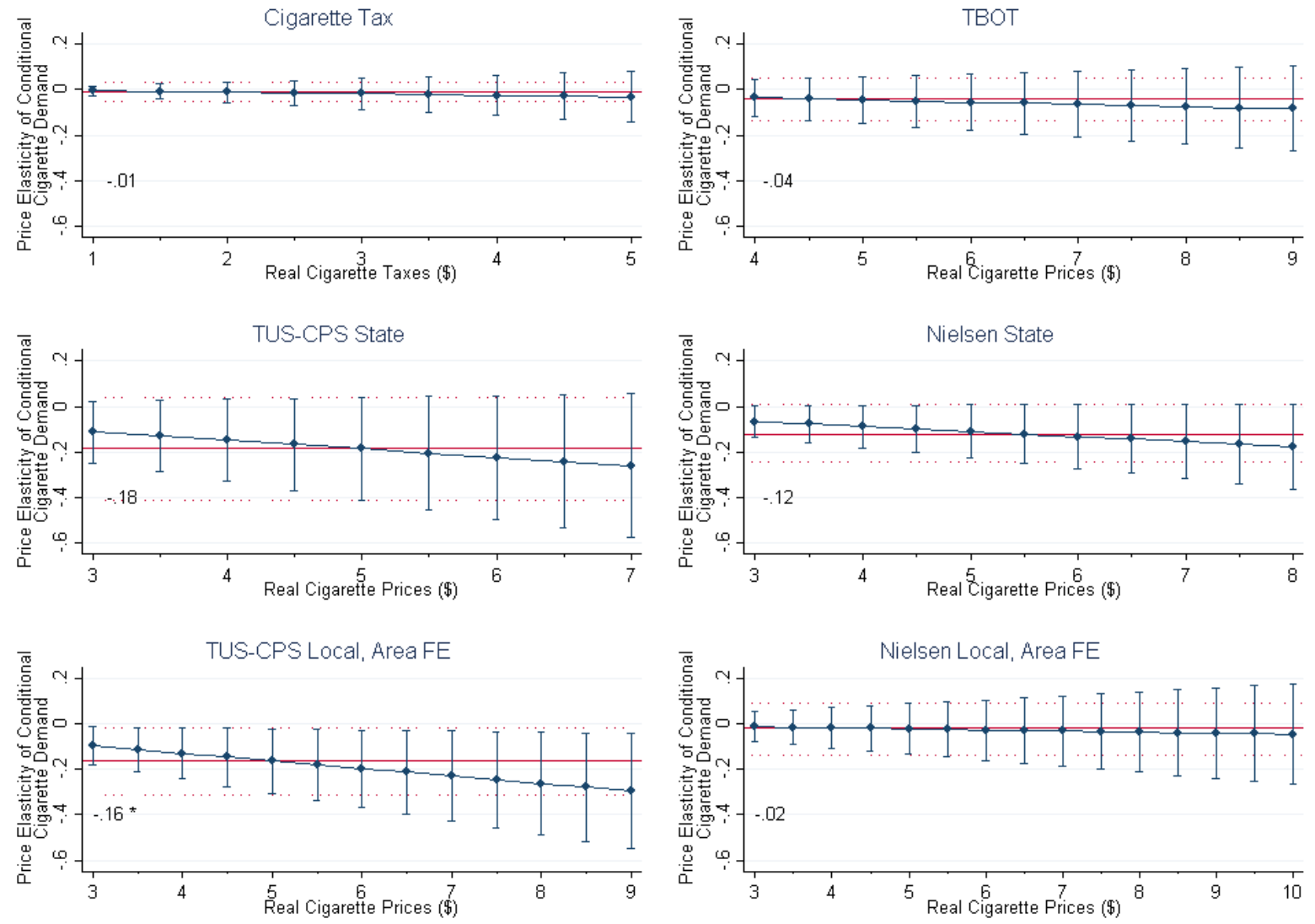

Notes: Conditional cigarette demand price elasticities are estimated using a GLM model with a log link and a Poisson distribution. Horizontal lines represent the average price elasticity and its $95 \%$ confidence interval. All regressions control for individual characteristics (gender, age, race/ethnicity, education, income, marital status, employment status), area-level characteristics (unemployment rate, indexes for smoking prohibitions in homes, public parts of workplaces, and private parts of workplaces, and antismoking sentiment measures for bars/clubs and playgrounds/sports fields), wave-by-month fixed effects, and either state fixed effects (first four graphs using state-level tax/price measures) or sub-state area fixed effects (last two graphs using local price measures). + Marginal effect is significant at the 5 percent level compared to the marginal effect at the lowest price level. * Average price elasticity significant at the 5 percent level. 
Figure 5: Total Cigarette Demand Price Elasticities Using Six Cigarette Price Measures, 2006-2015
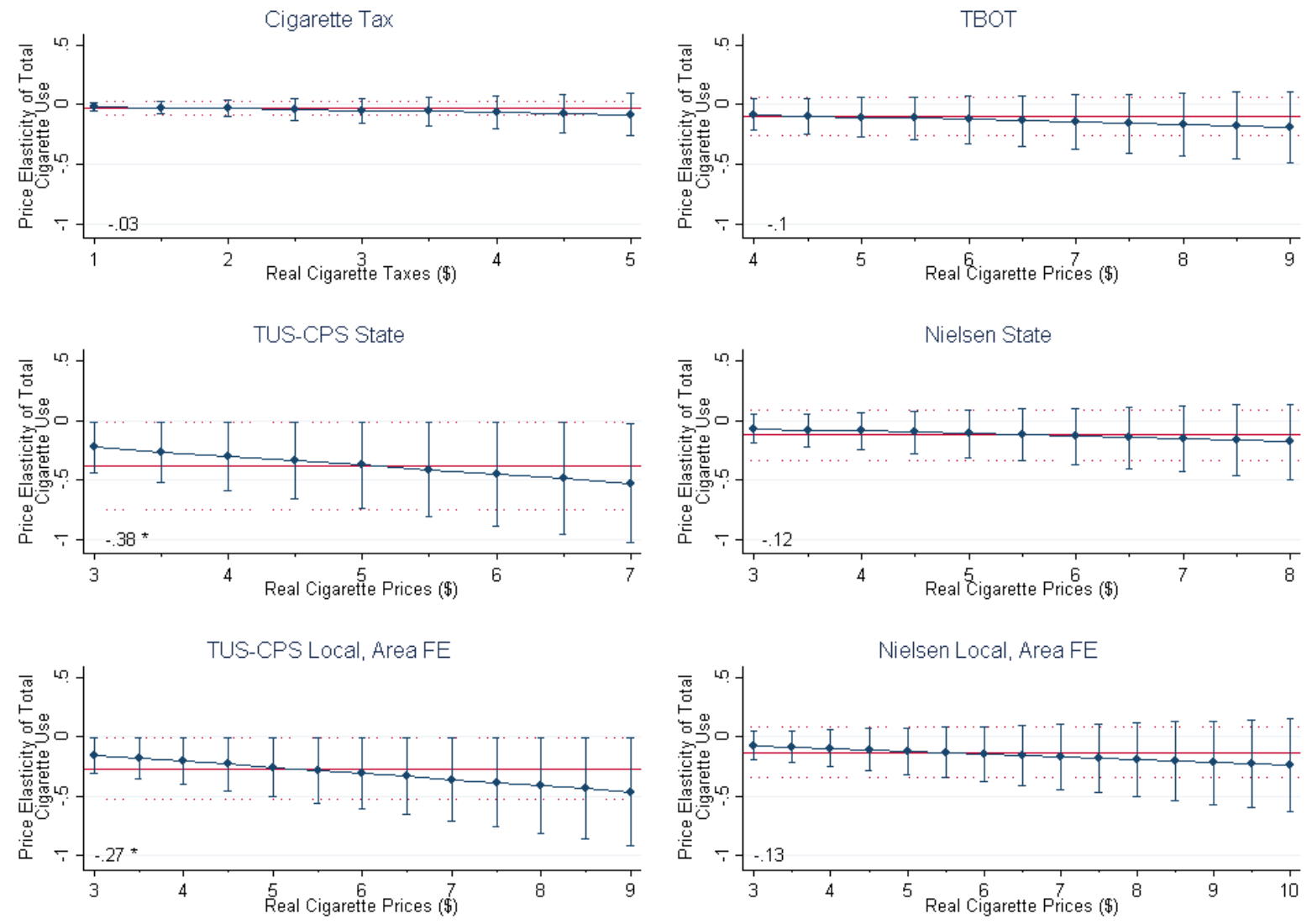

Notes: Total cigarette demand sets 30-day cigarette consumption for non-smokers to 0 and is estimated using a GLM model with a log link and a Poisson distribution. Horizontal lines represent the average price elasticity and its $95 \%$ confidence interval. All regressions control for individual characteristics (gender, age, race/ethnicity, education, income, marital status, employment status), area-level characteristics (unemployment rate, indexes for smoking prohibitions in homes, public parts of workplaces, and private parts of workplaces, and anti-smoking sentiment measures for bars/clubs and playgrounds/sports fields), wave-by-month fixed effects, and either state fixed effects (first four graphs using state-level tax/price measures) or sub-state area fixed effects (last two graphs using local price measures). + Marginal effect is significant at the 5 percent level compared to the marginal effect at the lowest price level. * Average price elasticity significant at the 5 percent level. 
Figure 6: Total Cigarette Demand Price Elasticities by Income, Age, and Education using Cigarette Excise Taxes, 2006-2015
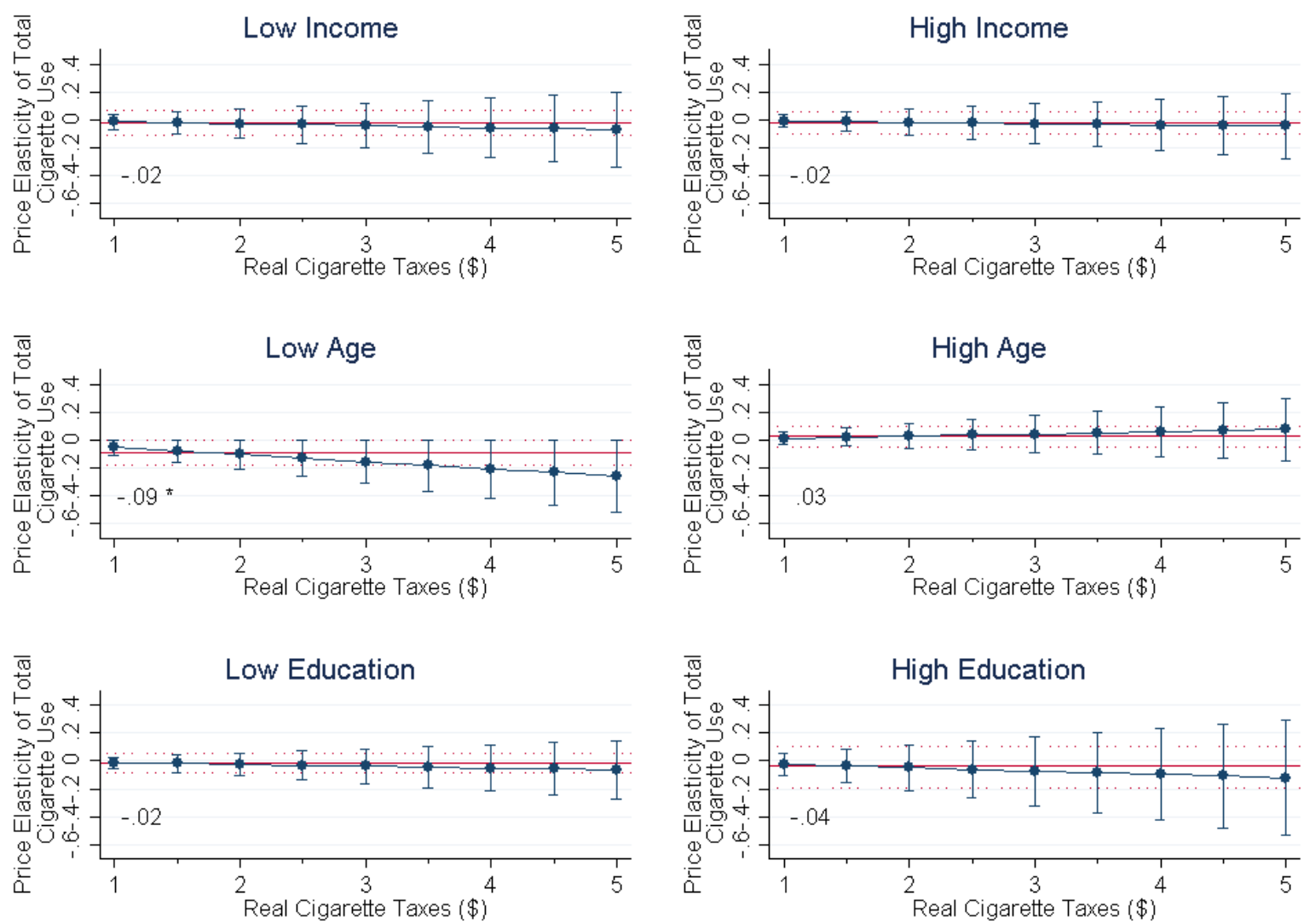

Notes: Each graph shows a separately estimated equation. Low age is $<45$, and high age is $\geq 45$. Low household income is $<\$ 40,000$, and high household income is $\geq \$ 40,000$. Low education is completed high school or less, and high education is completed some college or more. Total cigarette demand sets 30-day cigarette consumption for non-smokers to 0 and is estimated using a GLM model with a log link and a Poisson distribution. Horizontal lines represent the average price elasticity and its $95 \%$ confidence interval. + Marginal effect is significant at the 5 percent level compared to the marginal effect at the lowest price level. 
Figure 7: Total Cigarette Demand Price Elasticities by Income, Age, and Education using TBOT Prices, 2006-2015
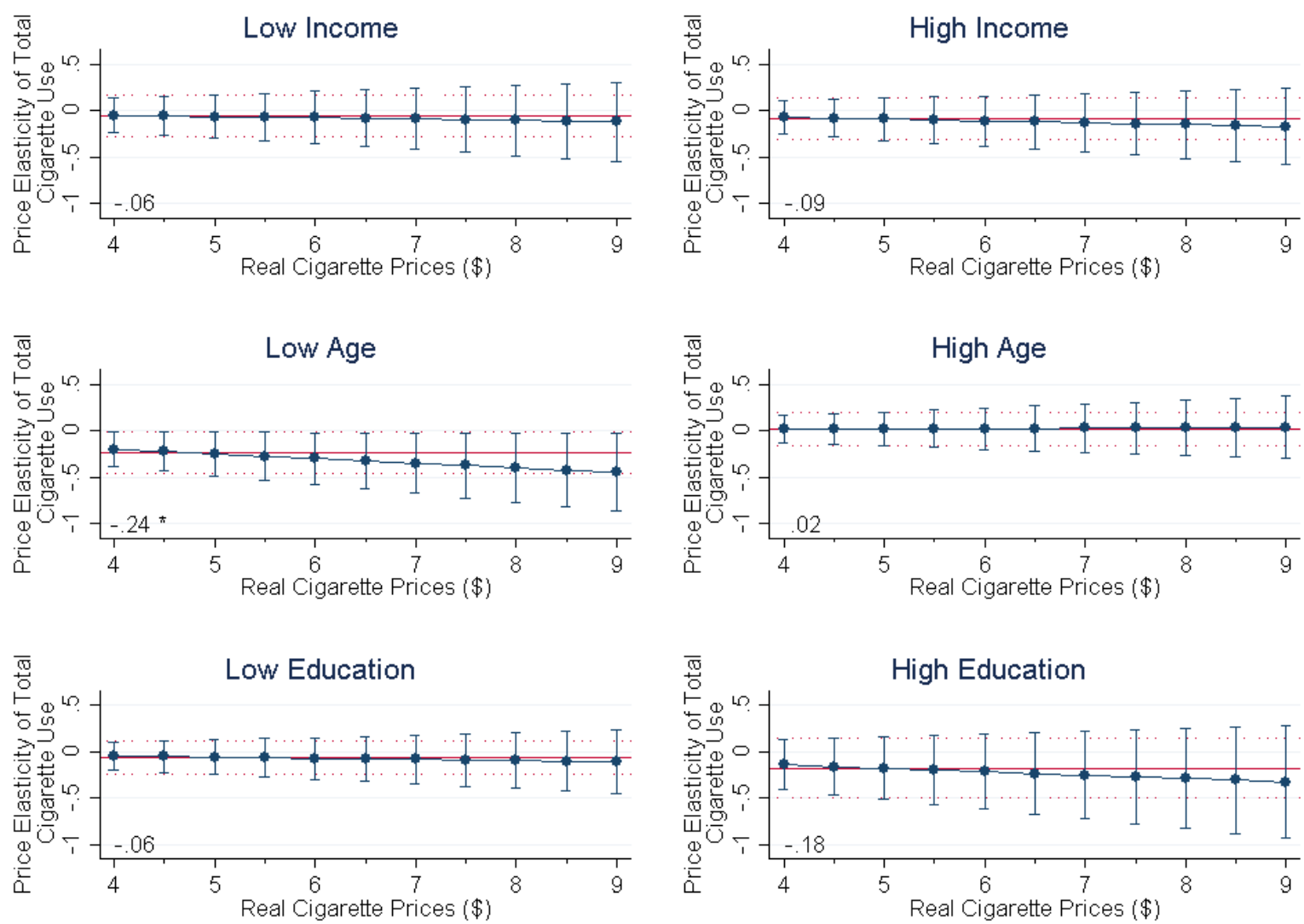

Notes: Each graph shows a separately estimated equation. Low age is $<45$, and high age is $\geq 45$. Low household income is $<\$ 40,000$, and high household income is $\geq \$ 40,000$. Low education is completed high school or less, and high education is completed some college or more. Total cigarette demand sets 30-day cigarette consumption for non-smokers to 0 and is estimated using a GLM model with a log link and a Poisson distribution. Horizontal lines represent the average price elasticity and its $95 \%$ confidence interval. + Marginal effect is significant at the 5 percent level compared to the marginal effect at the lowest price level. 
Figure 8: Total Cigarette Demand Price Elasticities by Income, Age, and Education using Nielsen State Prices, 2006-2015
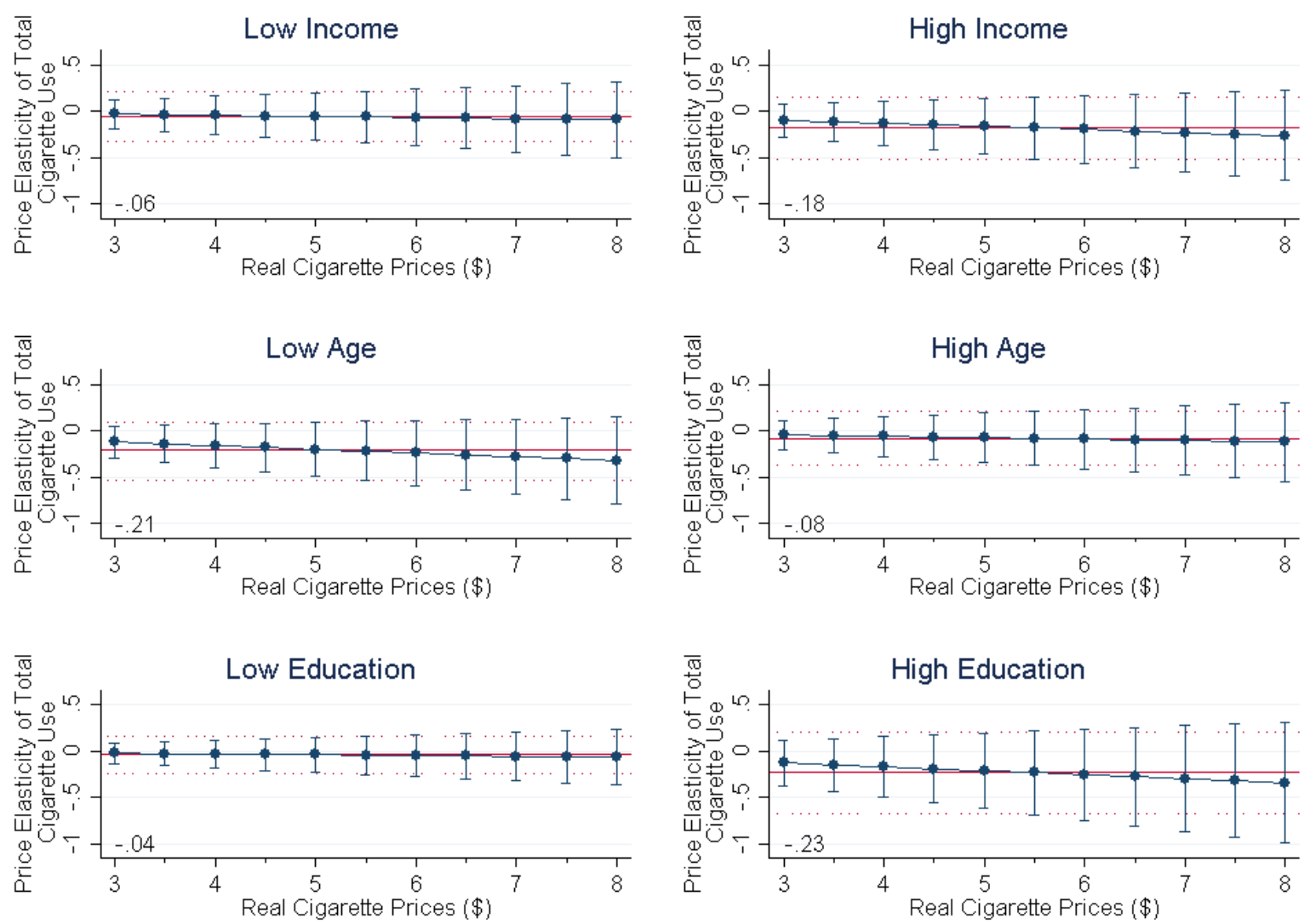

Notes: Each graph shows a separately estimated equation. Low age is $<45$, and high age is $\geq 45$. Low household income is $<\$ 40,000$, and high household income is $\geq \$ 40,000$. Low education is completed high school or less, and high education is completed some college or more. Total cigarette demand sets 30-day cigarette consumption for non-smokers to 0 and is estimated using a GLM model with a log link and a Poisson distribution. Horizontal lines represent the average price elasticity and its $95 \%$ confidence interval. + Marginal effect is significant at the 5 percent level compared to the marginal effect at the lowest price level. 
Figure 9: Total Cigarette Demand Price Elasticities by Income, Age, and Education using TUS-CPS State Prices, 2006-2015
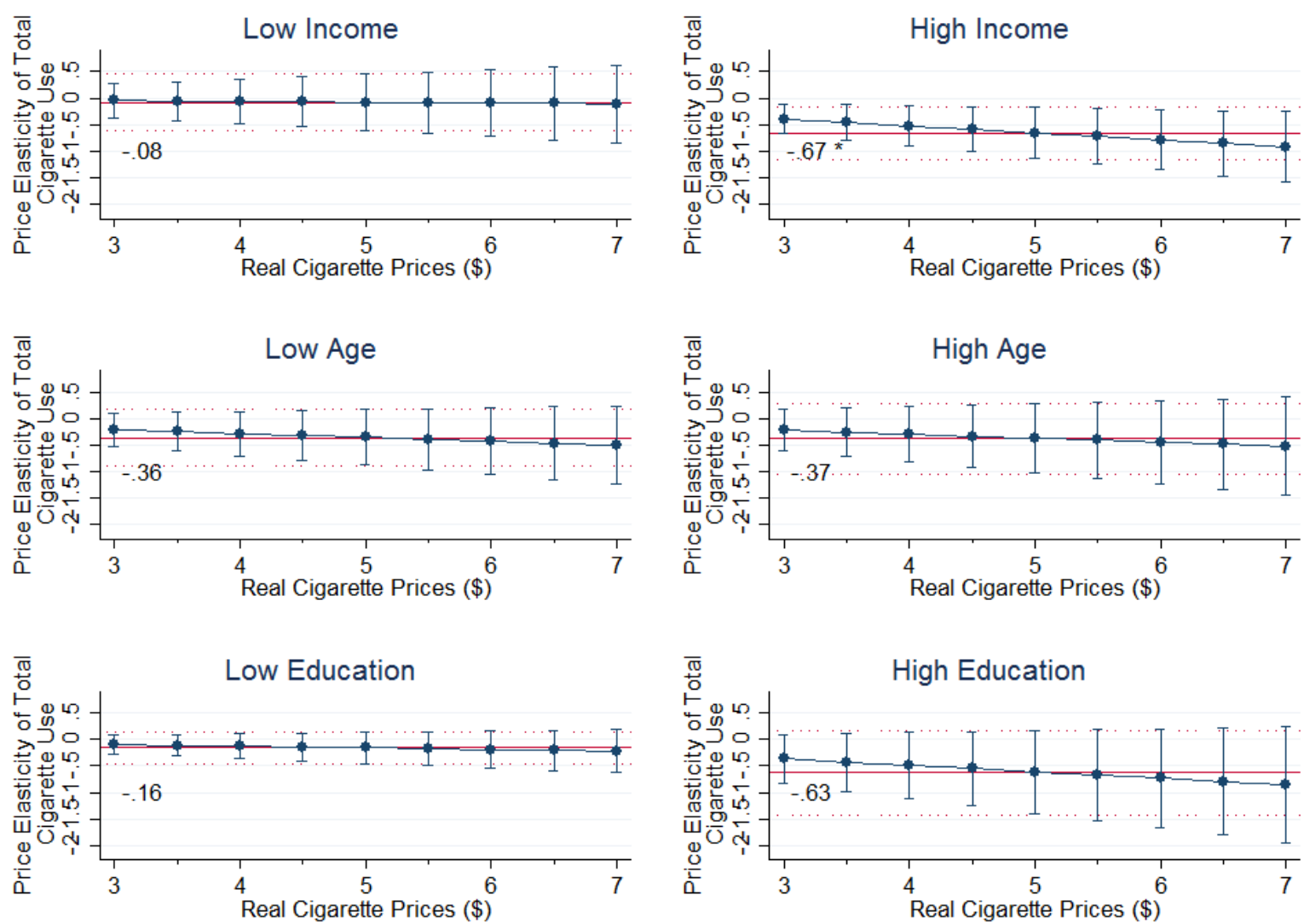

Notes: Each graph shows a separately estimated equation. Low age is $<45$, and high age is $\geq 45$. Low household income is $<\$ 40,000$, and high household income is $\geq \$ 40,000$. Low education is completed high school or less, and high education is completed some college or more. Total cigarette demand sets 30-day cigarette consumption for non-smokers to 0 and is estimated using a GLM model with a log link and a Poisson distribution. Horizontal lines represent the average price elasticity and its $95 \%$ confidence interval. + Marginal effect is significant at the 5 percent level compared to the marginal effect at the lowest price level. 
Online Table 1: Total Cigarette Demand GLM Coefficients Using Six Cigarette Price Measures, Full Results, 2006-2011

\begin{tabular}{|c|c|c|c|c|c|c|}
\hline & (1) & (2) & (3) & (4) & (5) & (6) \\
\hline \multirow[t]{2}{*}{ Male } & Ref & Ref & Ref & Ref & Ref & Ref \\
\hline & - & - & - & - & - & - \\
\hline \multirow[t]{2}{*}{ Female } & $-0.363 * * *$ & $-0.363 * * *$ & $-0.363 * * *$ & $-0.363 * * *$ & $-0.364 * * *$ & $-0.364 * * *$ \\
\hline & {$[0.028]$} & {$[0.028]$} & {$[0.028]$} & [0.028] & {$[0.028]$} & {$[0.028]$} \\
\hline \multirow[t]{2}{*}{ Age } & $0.160 * * *$ & $0.160 * * *$ & $0.160 * * *$ & $0.160 * * *$ & $0.160 * * *$ & $0.160 * * *$ \\
\hline & {$[0.004]$} & {$[0.004]$} & {$[0.004]$} & {$[0.004]$} & {$[0.004]$} & {$[0.004]$} \\
\hline \multirow[t]{2}{*}{ Age Squared } & $-0.002 * * *$ & $-0.002 * * *$ & $-0.002 * * *$ & $-0.002 * * *$ & $-0.002 * * *$ & $-0.002 * * *$ \\
\hline & {$[0.000]$} & {$[0.000]$} & {$[0.000]$} & {$[0.000]$} & {$[0.000]$} & {$[0.000]$} \\
\hline \multirow[t]{2}{*}{ White } & Ref & Ref & Ref & Ref & Ref & Ref \\
\hline & - & - & - & - & - & - \\
\hline \multirow[t]{2}{*}{ Black } & $-0.879 * * *$ & $-0.879 * * *$ & $-0.879 * * *$ & $-0.879 * * *$ & $-0.832 * * *$ & $-0.833 * * *$ \\
\hline & {$[0.048]$} & {$[0.048]$} & [0.048] & {$[0.048]$} & {$[0.049]$} & [0.049] \\
\hline \multirow[t]{2}{*}{ American Indian, Alaskan Native } & -0.068 & -0.068 & -0.068 & -0.068 & -0.073 & -0.072 \\
\hline & {$[0.153]$} & [0.153] & [0.153] & [0.153] & {$[0.145]$} & {$[0.145]$} \\
\hline \multirow[t]{2}{*}{ Asian, Hawaiian Pacific Islander } & $-1.133 * * *$ & $-1.133^{* * *}$ & $-1.134 * * *$ & $-1.133 * * *$ & $-1.040 * * *$ & $-1.041 * * *$ \\
\hline & {$[0.114]$} & {$[0.114]$} & {$[0.114]$} & {$[0.114]$} & {$[0.116]$} & {$[0.116]$} \\
\hline \multirow[t]{2}{*}{ Other Race } & 0.061 & 0.061 & 0.06 & 0.061 & 0.058 & 0.059 \\
\hline & {$[0.074]$} & {$[0.074]$} & {$[0.074]$} & {$[0.074]$} & {$[0.073]$} & [0.073] \\
\hline \multirow[t]{2}{*}{ Not Hispanic } & Ref & Ref & Ref & Ref & Ref & Ref \\
\hline & - & - & - & - & - & - \\
\hline \multirow[t]{2}{*}{ Hispanic } & $-1.439 * * *$ & $-1.439 * * *$ & $-1.440 * * *$ & $-1.439 * * *$ & $-1.356 * * *$ & $-1.356 * * *$ \\
\hline & [0.068] & {$[0.068]$} & [0.068] & [0.068] & [0.073] & {$[0.073]$} \\
\hline \multirow[t]{2}{*}{ Less than High School } & Ref & Ref & Ref & Ref & Ref & Ref \\
\hline & - & - & - & - & - & - \\
\hline \multirow[t]{2}{*}{ High School Only } & $-0.264 * * *$ & $-0.264 * * *$ & $-0.264 * * *$ & $-0.264 * * *$ & $-0.258 * * *$ & $-0.259 * * *$ \\
\hline & {$[0.032]$} & {$[0.032]$} & {$[0.032]$} & {$[0.032]$} & {$[0.031]$} & {$[0.031]$} \\
\hline \multirow[t]{2}{*}{ More than High School } & $-0.938 * * *$ & $-0.938 * * *$ & $-0.938 * * *$ & $-0.938 * * *$ & $-0.910 * * *$ & $-0.910 * * *$ \\
\hline & {$[0.034]$} & {$[0.034]$} & {$[0.034]$} & {$[0.034]$} & {$[0.034]$} & {$[0.034]$} \\
\hline \multirow[t]{2}{*}{$\begin{array}{l}\text { Family Income (Top Coded at } \\
\$ 75,000)\end{array}$} & $-0.000 * * *$ & $-0.000 * * *$ & $-0.000 * * *$ & $-0.000 * * *$ & $-0.000 * *$ & $-0.000 * *$ \\
\hline & {$[0.000]$} & {$[0.000]$} & {$[0.000]$} & {$[0.000]$} & {$[0.000]$} & {$[0.000]$} \\
\hline \multirow[t]{2}{*}{ Family Income Squared } & $-0.000 * *$ & $-0.000 * *$ & $-0.000 * *$ & $-0.000 * *$ & $-0.000 * *$ & $-0.000 * *$ \\
\hline & {$[0.000]$} & {$[0.000]$} & {$[0.000]$} & {$[0.000]$} & {$[0.000]$} & {$[0.000]$} \\
\hline \multirow[t]{2}{*}{ Family Income Non-Top Categories } & Ref & Ref & Ref & Ref & Ref & Ref \\
\hline & - & - & - & - & - & - \\
\hline \multirow[t]{2}{*}{ Family Income Top Category } & $-0.210 * * *$ & $-0.210 * * *$ & $-0.209 * * *$ & $-0.210 * * *$ & $-0.186 * * *$ & $-0.185 * * *$ \\
\hline & {$[0.052]$} & {$[0.052]$} & {$[0.052]$} & {$[0.052]$} & {$[0.049]$} & {$[0.049]$} \\
\hline \multirow[t]{2}{*}{ Married (No) } & Ref & Ref & Ref & Ref & Ref & Ref \\
\hline & - & - & - & - & - & - \\
\hline \multirow[t]{2}{*}{ Married (Yes) } & $0.418^{* * *}$ & $0.418^{* * *}$ & $0.418^{* * *}$ & $0.418^{* * *}$ & $0.429 * * *$ & $0.430 * * *$ \\
\hline & {$[0.028]$} & {$[0.028]$} & {$[0.028]$} & {$[0.028]$} & {$[0.029]$} & {$[0.030]$} \\
\hline \multirow[t]{2}{*}{ Employed and Working } & Ref & Ref & Ref & Ref & Ref & Ref \\
\hline & - & - & - & - & - & - \\
\hline Unemployed & $0.415^{* * *}$ & $0.415^{* * *}$ & $0.415^{* * *}$ & $0.415^{* * *}$ & $0.417^{* * *}$ & $0.417 * * *$ \\
\hline & {$[0.037]$} & {$[0.037]$} & {$[0.037]$} & {$[0.037]$} & {$[0.036]$} & {$[0.036]$} \\
\hline Not In Labor Force & $0.188^{* * *}$ & $0.188^{* * *}$ & $0.188^{* * *}$ & $0.188^{* * *}$ & $0.185^{* * *}$ & $0.185^{* * *}$ \\
\hline & {$[0.024]$} & {$[0.024]$} & {$[0.024]$} & {$[0.024]$} & {$[0.023]$} & {$[0.023]$} \\
\hline Area Unemployment Rate & 0.278 & 0.279 & 0.287 & 0.278 & $0.573 *$ & $0.559 *$ \\
\hline & {$[0.237]$} & {$[0.237]$} & {$[0.237]$} & {$[0.237]$} & {$[0.331]$} & [0.329] \\
\hline $\begin{array}{l}\text { Area Index for Smoking Not } \\
\text { Permitted in Home }\end{array}$ & $-0.577 * * *$ & $-0.577 * * *$ & $-0.573 * * *$ & $-0.577 * * *$ & 0.157 & 0.145 \\
\hline
\end{tabular}




\begin{tabular}{|c|c|c|c|c|c|c|}
\hline & [0.158] & [0.159] & {$[0.156]$} & [0.159] & {$[0.170]$} & [0.167] \\
\hline \multirow[t]{2}{*}{$\begin{array}{c}\text { Area Index for Smoking Not } \\
\text { Permitted in Private Parts of } \\
\text { Workplace }\end{array}$} & 0.252 & 0.253 & 0.261 & 0.251 & $0.443 * *$ & $0.409 * *$ \\
\hline & {$[0.212]$} & {$[0.212]$} & [0.215] & {$[0.212]$} & {$[0.184]$} & [0.190] \\
\hline \multirow[t]{2}{*}{$\begin{array}{c}\text { Area Index for Smoking Not } \\
\text { Permitted in Public Parts of } \\
\text { Workplace }\end{array}$} & -0.213 & -0.212 & -0.221 & -0.211 & $-0.248 * *$ & $-0.218^{*}$ \\
\hline & [0.131] & [0.132] & [0.133] & [0.131] & [0.115] & [0.113] \\
\hline \multirow[t]{2}{*}{$\begin{array}{l}\text { Area Anti-Smoking Sentiment for } \\
\text { Bars/Clubs }\end{array}$} & $-0.639 * * *$ & $-0.636 * * *$ & $-0.642 * * *$ & $-0.636 * * *$ & -0.089 & -0.101 \\
\hline & {$[0.148]$} & [0.149] & {$[0.147]$} & {$[0.148]$} & {$[0.154]$} & [0.154] \\
\hline \multirow[t]{2}{*}{$\begin{array}{c}\text { Area Anti-Smoking Sentiment for } \\
\text { Children's Playgrounds/Sports } \\
\text { Fields }\end{array}$} & 0.185 & 0.18 & 0.192 & 0.181 & 0.096 & 0.104 \\
\hline & [0.152] & [0.153] & {$[0.154]$} & [0.152] & {$[0.157]$} & [0.162] \\
\hline \multirow[t]{2}{*}{ State and Federal Taxes } & -0.044 & & & & & \\
\hline & [0.029] & & & & & \\
\hline \multirow[t]{2}{*}{$\begin{array}{c}\text { Tax Burden on Tobacco Cigarette } \\
\text { Prices } \\
\end{array}$} & & -0.031 & & & & \\
\hline & & [0.024] & & & & \\
\hline \multirow[t]{2}{*}{ TUS-CPS State Price } & & & $-0.076 *$ & & & \\
\hline & & & {$[0.044]$} & & & \\
\hline \multirow[t]{2}{*}{ Nielsen State Price } & & & & -0.026 & & \\
\hline & & & & {$[0.024]$} & & \\
\hline \multirow[t]{2}{*}{ TUS-CPS Local Price } & & & & & $-0.051 * * *$ & \\
\hline & & & & & {$[0.019]$} & \\
\hline \multirow[t]{2}{*}{ Nielsen Local Price } & & & & & & -0.024 \\
\hline & & & & & & {$[0.015]$} \\
\hline \multirow[t]{2}{*}{ Constant } & $4.693 * * *$ & $4.780 * * *$ & $4.851 * * *$ & $4.753^{* * *}$ & $1.546 * *$ & $1.521 * *$ \\
\hline & {$[0.530]$} & [0.519] & {$[0.515]$} & {$[0.520]$} & [0.637] & [0.639] \\
\hline Sample Size & 489,485 & 489,485 & 489,485 & 489,485 & 489,485 & 489,485 \\
\hline State Fixed Effects & $\mathrm{x}$ & $\mathrm{x}$ & $\mathrm{x}$ & $\mathrm{x}$ & & \\
\hline Area Fixed Effects & & & & & $\mathrm{X}$ & $\mathrm{X}$ \\
\hline Wave-by-Month Fixed Effects & $\mathrm{X}$ & $x$ & $\mathrm{X}$ & $x$ & $\mathrm{x}$ & $\mathrm{x}$ \\
\hline
\end{tabular}

Notes: Total cigarette demand sets 30-day cigarette consumption for non-smokers to 0 and is estimated using a GLM model with a log link and a Poisson distribution. * Significant at the 10 percent level, ** Significant at the 5 percent level, *** Significant at the 1 percent level. 

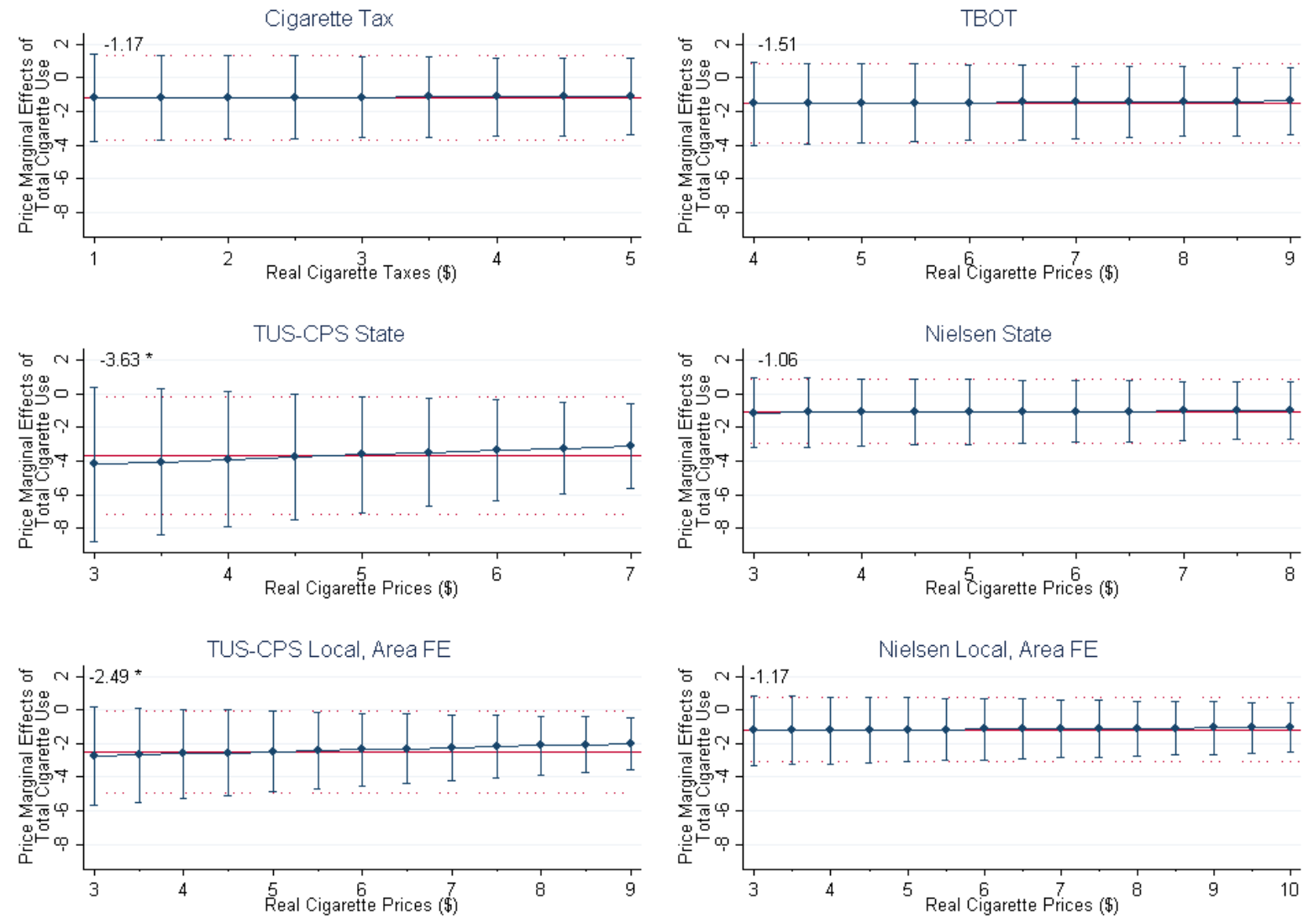

Notes: Total cigarette demand sets 30-day cigarette consumption for non-smokers to 0 and is estimated using a GLM model with a log link and a Poisson distribution. Horizontal lines represent the average price marginal effect and its $95 \%$ confidence interval. All regressions control for individual characteristics (gender, age, race/ethnicity, education, income, marital status, employment status), area-level characteristics (unemployment rate, indexes for smoking prohibitions in homes, public parts of workplaces, and private parts of workplaces, and anti-smoking sentiment measures for bars/clubs and playgrounds/sports fields), wave-by-month fixed effects, and either state fixed effects (first four graphs using state-level tax/price measures) or sub-state area fixed effects (last two graphs using local price measures). + Marginal effect is significant at the 5 percent level compared to the marginal effect at the lowest price level. * Average marginal effect significant at the 5 percent level. 
Online Figure 2: Cigarette Demand Price Elasticities (Extensive, Intensive, and Total) for TUS-CPS State Prices from In-State Purchases, 2006-2015
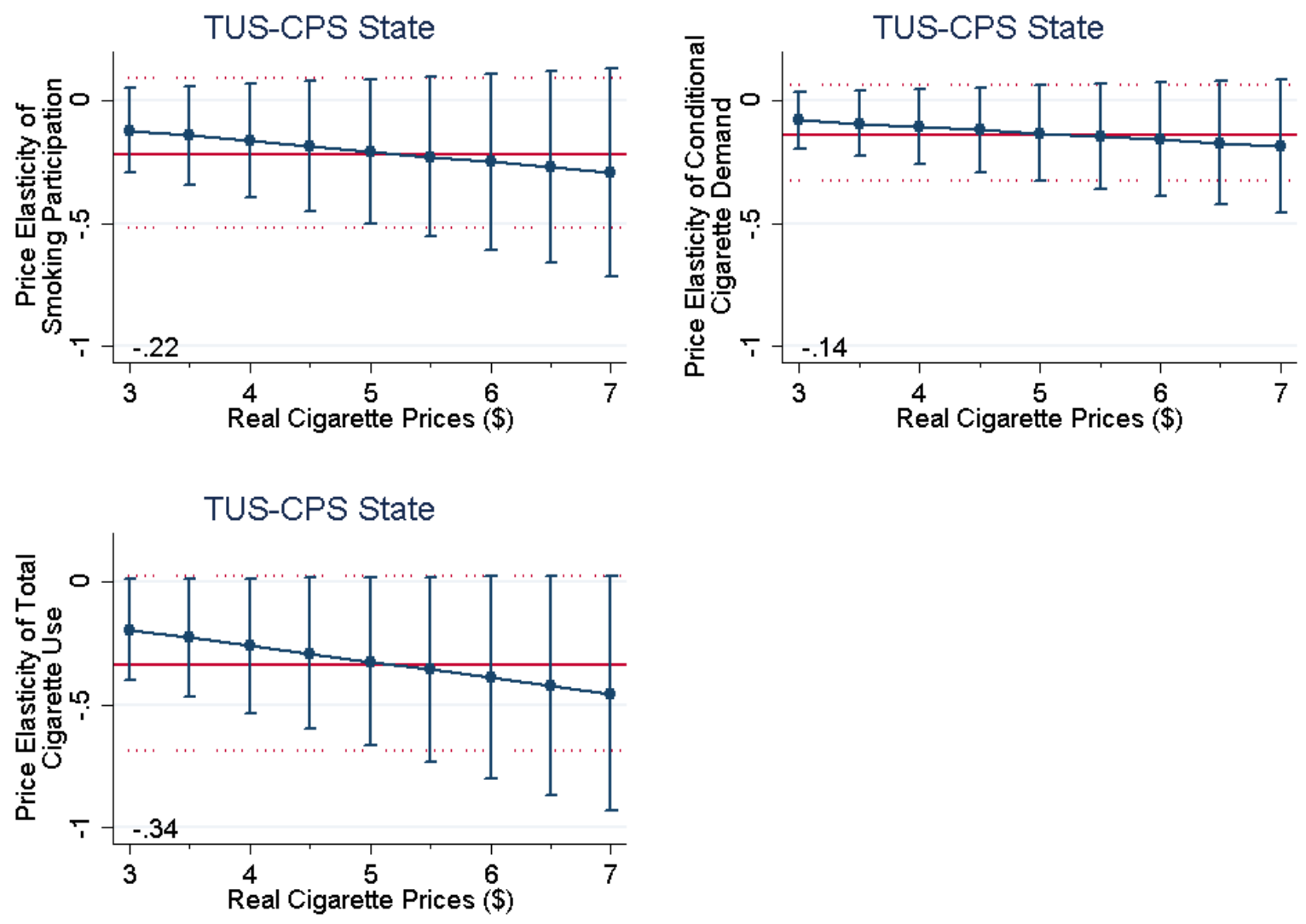

Notes: Total cigarette demand sets 30-day cigarette consumption for non-smokers to 0 and is estimated using a GLM model with a log link and a Poisson distribution. Horizontal lines represent the average price marginal effect and its $95 \%$ confidence interval. All regressions control for individual characteristics (gender, age, race/ethnicity, education, income, marital status, employment status), area-level characteristics (unemployment rate, indexes for smoking prohibitions in homes, public parts of workplaces, and private parts of workplaces, and anti-smoking sentiment measures for bars/clubs and playgrounds/sports fields), wave-by-month fixed effects, and state fixed effects. + Marginal effect is significant at the 5 percent level compared to the marginal effect at the lowest price level. * Average marginal effect significant at the 5 percent level. 